\title{
Flow charts for use in leprosy control programmes
}

\author{
S J NICKLESS \\ Student Health Service, London School of Economics, London \\ $W C 2 A 2 A E$
}

Accepted for publication 27 April 1985

\section{Introduction}

These charts were developed as a personal exercise during a visit to Green Pastures Leprosy Hospital, Pokhara, Nepal. They are an attempt to summarize in a readily accessible format the clinical and administrative 'standing orders' which govern the work of leprosy control project paramedical workers in remote clinics. They could be modified and translated for use in other settings.

\section{Purpose of flow charts}

The charts do not cover the diagnosis and classification of leprosy. They are intended to be used in the follow-up of patients once appropriate therapy has been initiated. Such patients constitute the majority of attenders at leprosy clinics.

\section{CHARTS 1 AND 2}

These cover the routine assessment of patients on multidrug therapy (MDT) and the decision to discharge those who have completed treatment. The charts select those patients who may have potentially serious problems and divert them to charts 3 and 4 for fuller assessment. All patients must progress to one of the end points on chart 2 .

\section{CHARTS 3 AND 4}

These deal with selected 'problem patients' currently receiving MDT and discharged patients returning with immunological reactivation or bacteriological relapse. The chart does not differentiate types of reaction but directs attention to the symptoms and severity of the reaction and its initial management.

Policy in Western Nepal is to refer to hospital all patients with reactions and other significant problems. LCP paramedics have Aspirin, chloroquine, atropine and steroids to initiate treatment. 


\section{Use of flow charts}

The major use of these charts would be in the education of new staff. Conventional teaching methods pass on large quantities of confusing and seemingly unrelated detail. These charts integrate and organize this material and direct attention to the only important question, 'What should I do now for this patient?'

Students could use the charts under supervision at an early stage in their training. They would rapidly assimilate the content and logic of the charts. 'Learning by doing' increases confidence, teaches decision making and reinforces classroom teaching.

The charts could also be a usef ul 'aide-memoire' for health workers who only see an occasional leprosy patient.

\section{Acknowledgments}

I would like to thank H Bedenbender, Leprosy Control project Staffworker of Pokhara, Nepal and Dr F Ross of the American Leprosy Mission for helpful advice.

Chart 1(a). Compliance-adherence to prescribed medication.

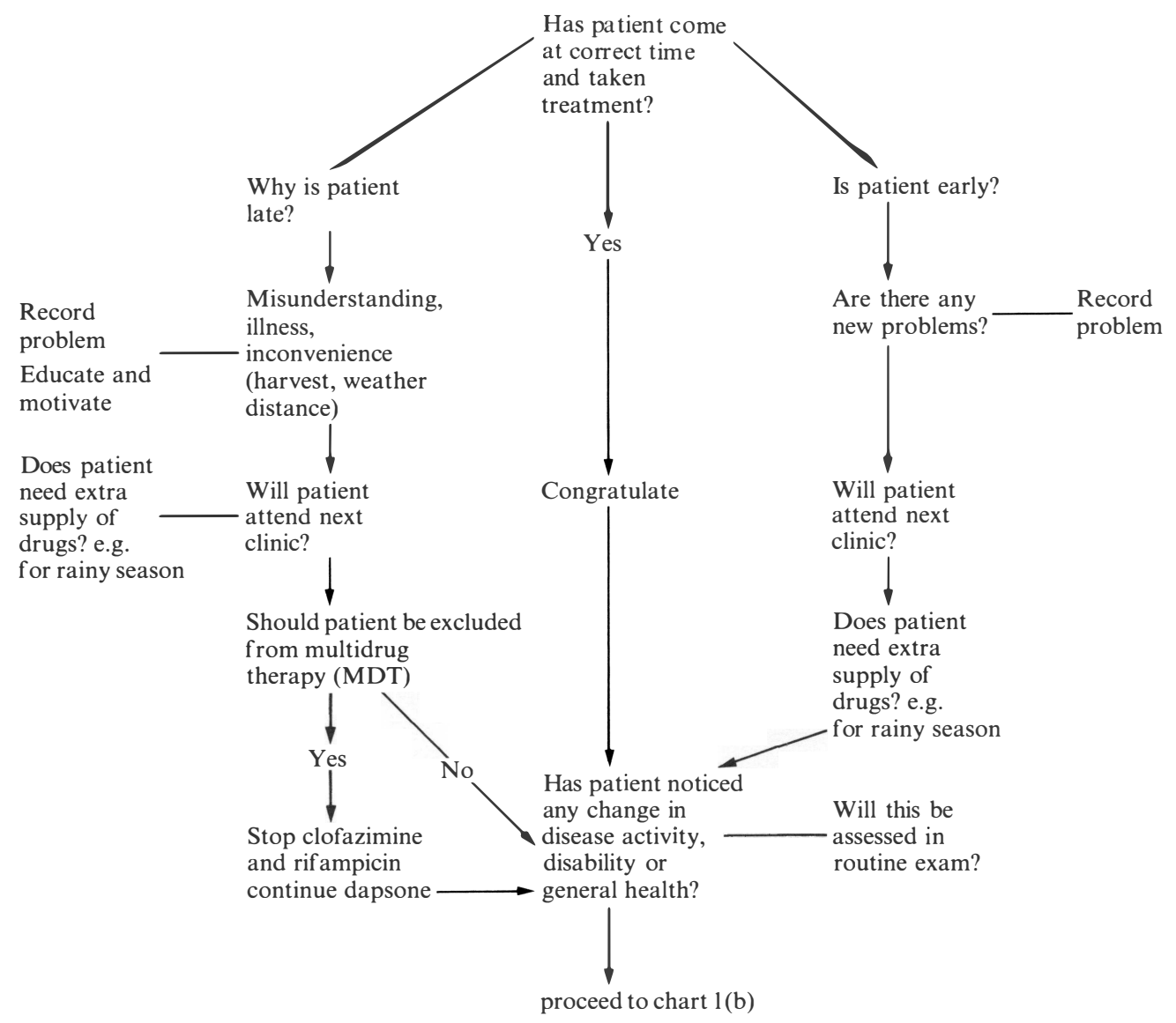


Chart 1(b). Clinical examination and assessment.

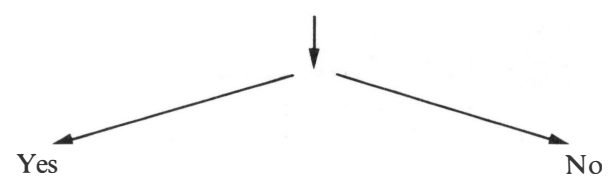

Full examination of skin, nerves,

Routine check of skin, nerves,

eyes, disabilities and general health and skin smears eyes, disabilities and general health

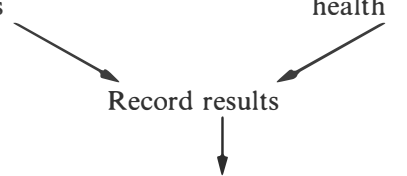

(a) Has there been

any change in

disease activity?

-eyes

-skin lesions

-nerve tenderness $\rightarrow$ Yes $\rightarrow \underset{\text { reactions }}{\text { Consider }} \rightarrow$ Proceed to Chart 3<smiles>[3H][CH]</smiles>

(b) Has there been

any change

in disability?

Proceed to

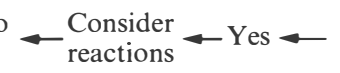

-anaesthesia

-weakness

Chart 3 reactions

-paralysis<smiles></smiles>

(c) Has there been any change in general health?

-cough -weight loss

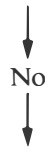

Proceed to Chart 2

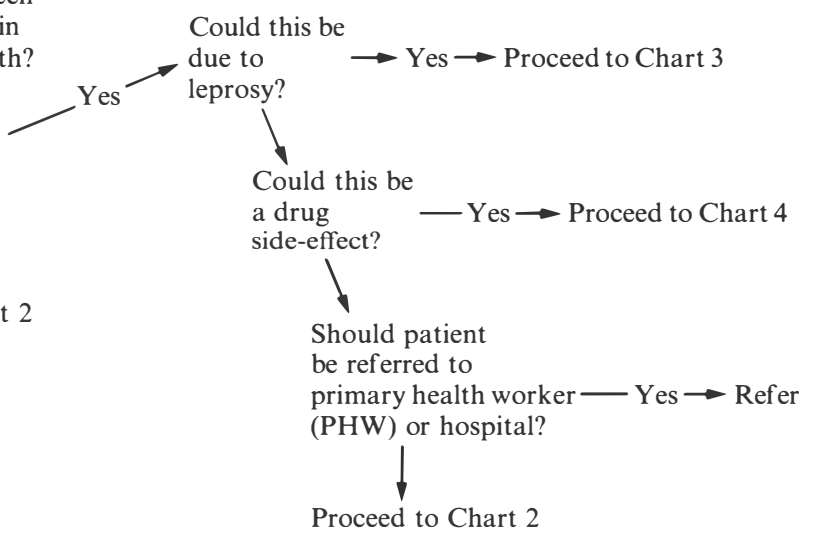


Chart 2(a) Supervision of multidrug therapy.

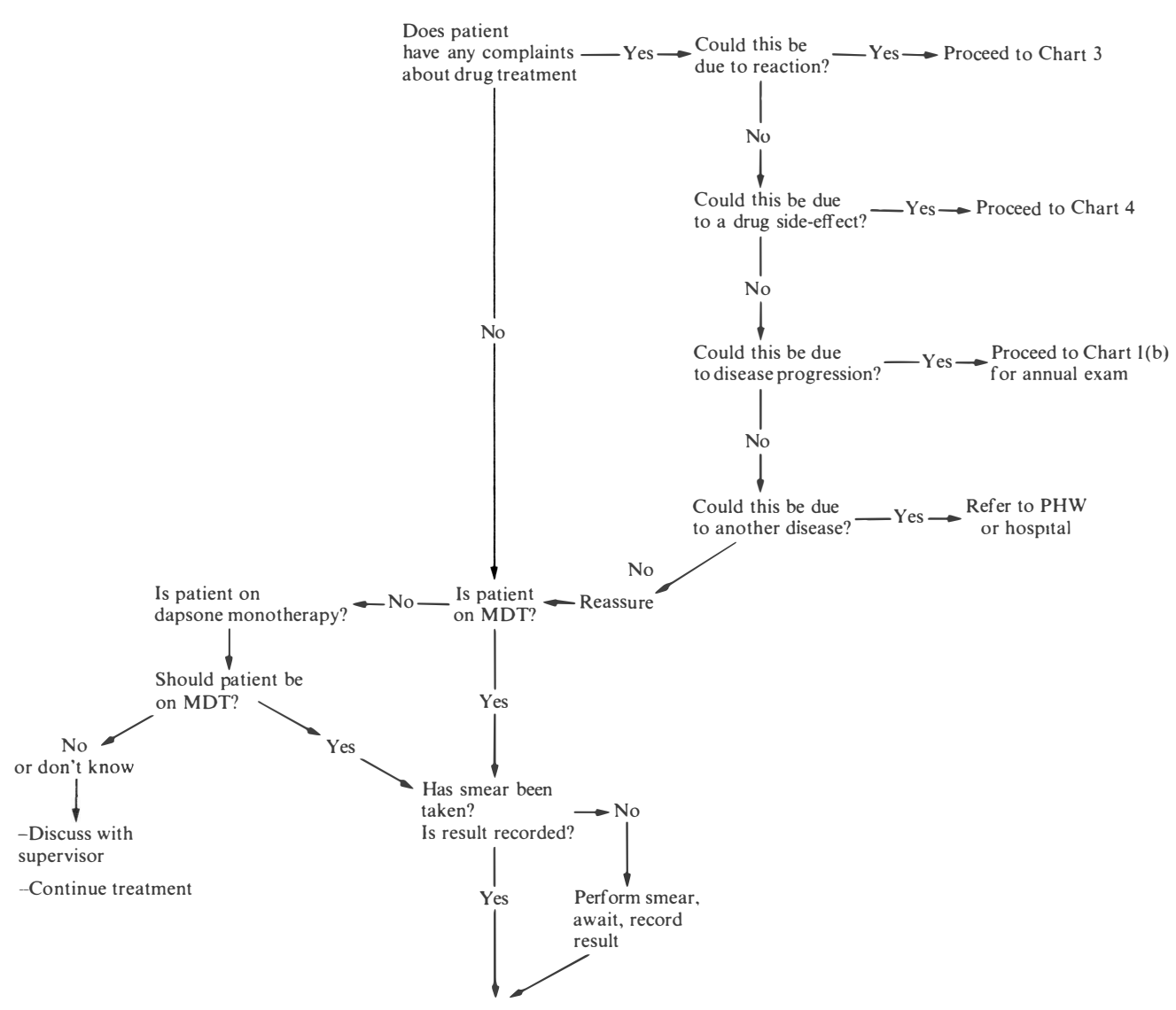


Chart 2(b). Duration of multidrug therapy.

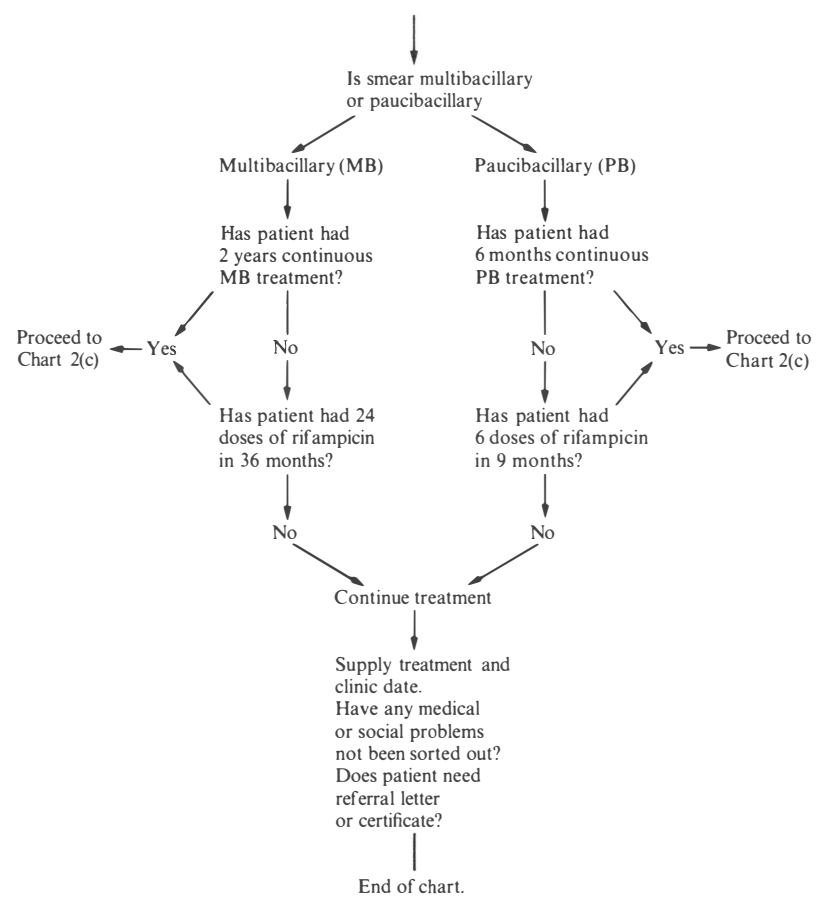

Chart 2(c). Progress and termination of multidrug therapy.

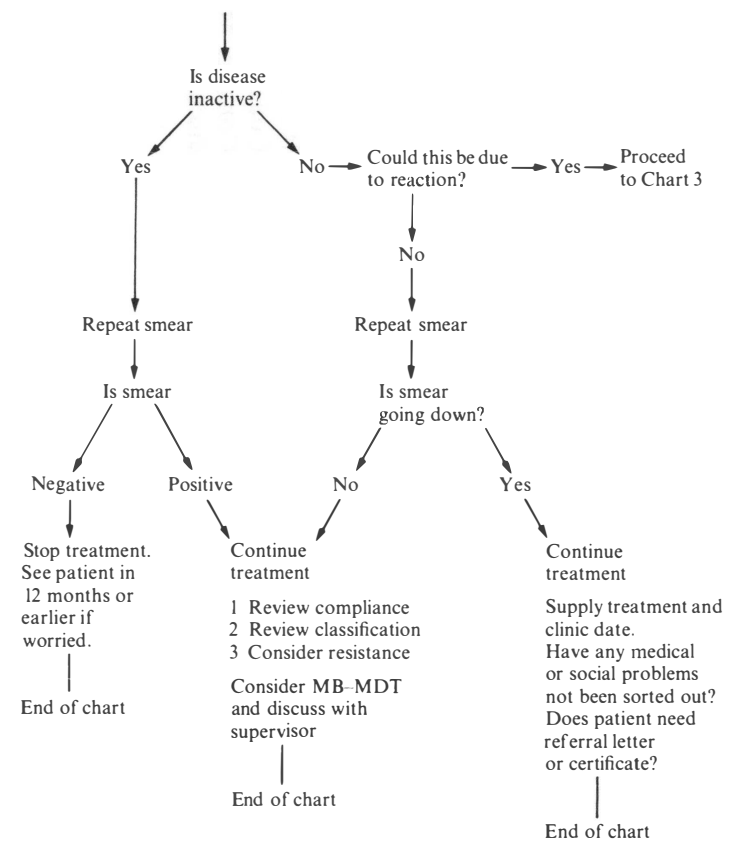


Chart 3. Problems, reactions and relapse.
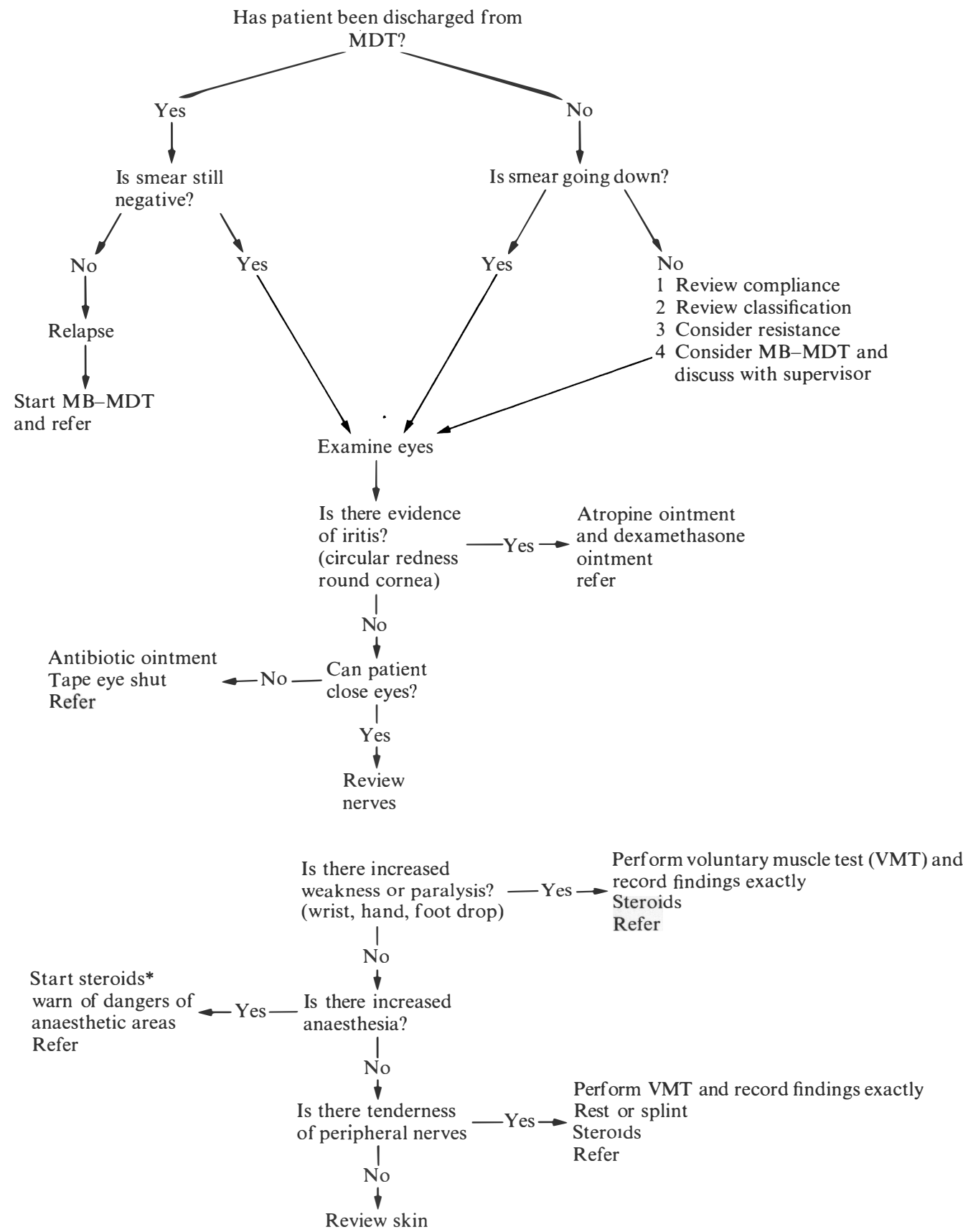
Chart 3 (cont.)

Continue MDT

Start Aspirin* and/or chloroquine and refer

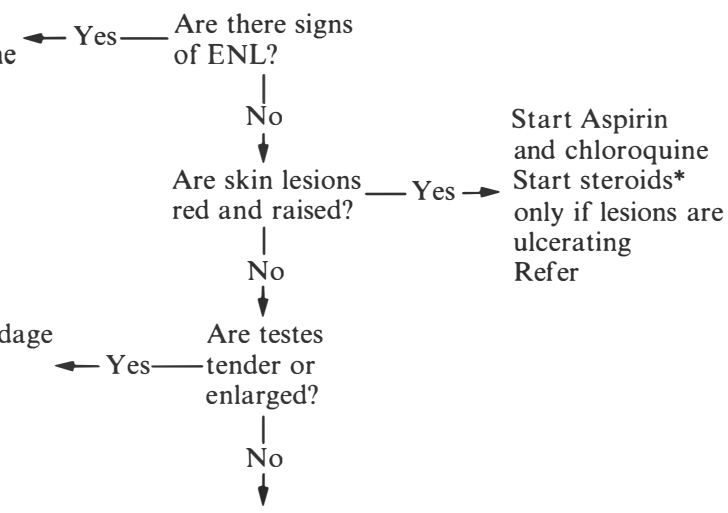
Does patient have ulcers
needing hospital care?

Suspensory bandage

Antibiotic

Start Aspirin

ulcerating

Refer

No

Record in patient's card

Complete forms

Report to leprosy supervisor

and regional office

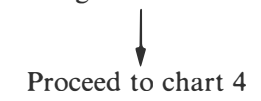

* Do not use Aspirin and steroids together. 
Chart 4. Medical problems and drug side-effects.

Does patient complain of nausea and vomiting?

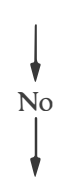

May be due to any drug or another illness.

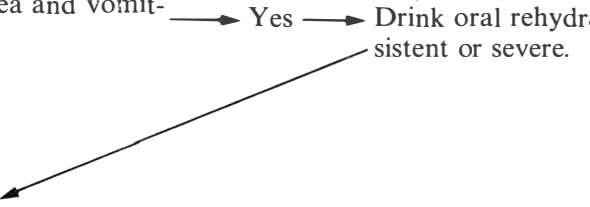

Does patient c/o dermatitis? (Red, itchy flaky skin)

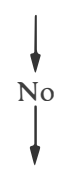

Does patient c/o bruising or bleeding?
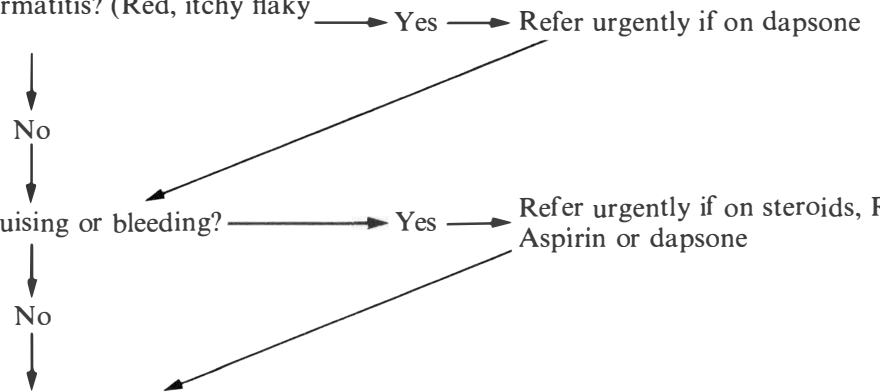

Refer urgently if on steroids, Rifampicin Aspirin or dapsone

Does patient c/o abdominal pain and black or red stools?
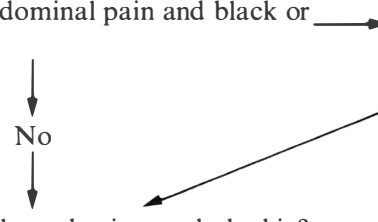

Yes $\longrightarrow$ Refer urgently

Does patient c/o coloured urine or dark skin?
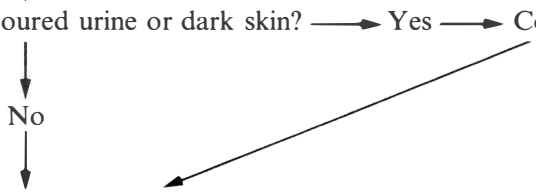

Unimportant if due to clofazimine or rifampicin

Consider - social problems

- non-infectious certificate

- Local health education.

Does patient look jaundiced? (yellow eyes and skin)

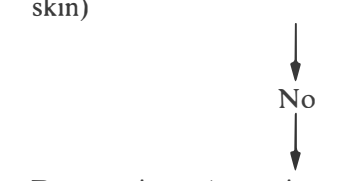

Does patient c/o persistent fever?

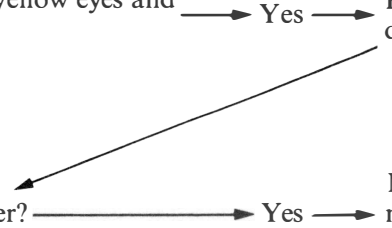

Refer urgently. May be due to Rifampicin, dapsone or medical problem.
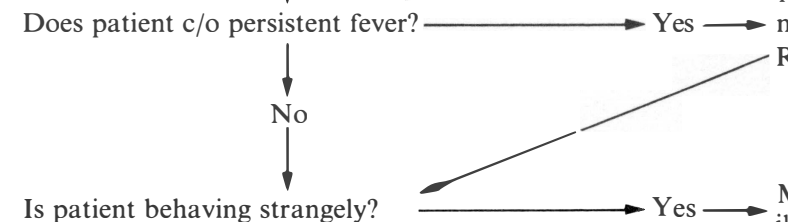

May be due to erythema nodosum leprosum, minor illness, TB, malaria, ENL or rifampicin. Refer if persistent, ill, cough or weight loss.

Is patient behaving strangely?

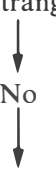

Has there been any change in general health?

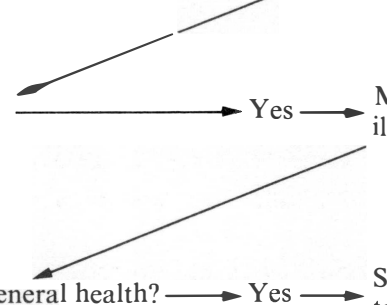

May be due to steroids, chloroquine or other illness. Refer if severe.

No

Should patient be referred to PHW or hospital? Refer.

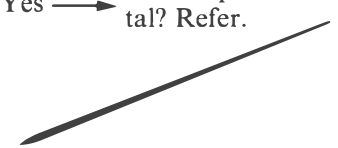

Proceed to previous place on flow chart. 